\title{
INVENTARISASI DAN IDENTIFIKASI TUMBUHAN AIR DI DANAU HANJALUTUNG KOTA PALANGKA RAYA
}

\author{
Inventory and Identification of Water Plants In Lake Hanjalutung \\ Palangka Raya City
}

\author{
Ummi Suraya \\ Jurusan Perikanan Fakultas Pertanian Universitas Palangka Raya \\ Email : surayaummi@yahoo.co.id
}

\begin{abstract}
The aim of this research is to identify and to inventory water plants in Hanjalutung Lake,Petuk Ketimpun Village, Jekan Raya District, Palangka Raya City. This research was conducted from December 2017 to January 2018. Sampling was carried out in 3 (three) stations, namely inlet, middle and outlet. The tool used for aquatic plants $2 \mathrm{x} 2 \mathrm{~m}$ transect.The results of research aquatic plants found in the waters of Lake Hanjalutung 7 (seven) types namely Kiambang (Salvinia molesta), gerigit/bite (Leersia hexandra), Cat Tail Grass (Utricularia aurea), Para Grass (Cyperus platystylis), Water Hyacinth ( Eichhornia crassipes ), Kiapu (Pistia stratiotes) dan Ketanan (Polygonum sp).
\end{abstract}

Keywords : identifikasi water plant, lake Hanjalutung

\begin{abstract}
ABSTRAK
Penelitian ini bertujuan untuk megidentifikasi serta mengiventarisasi tumbuhan air yang ada di Danau Hanjalutung Kelurahan Petuk Ketimpun, Kecamatan Jekan Raya, Kota Palangka Raya. Penelitian ini dilakukan selama 1 (satu) bulan yaitu pada bulan Desember 2017 sampai Januari 2018. Dan pengambilan sampel dilakukan di 3 (tiga) stasiun yaitu inlet (stasiun I), bagian tengah (stasiun II) dan outlet (stasiun III). Sedangkan alat yang digunakan untuk pengambilan sampel tumbuhan air yaitu menggunakan transek berukuran $2 \times 2 \mathrm{~m}$. Adapun hasil penelitian tumbuhan air yang ditemukan pada pada perairan Danau Hanjalutung yaitu 7 (tujuh) jenis tumbuhan air yaitu Kiambang (Salvinia molesta), gerigit (Leersia hexandra), Rumput Ekor Kucing (Utricularia aurea), Rumput Para (Cyperus platystylis), Eceng Gondok (Eichhornia crassipes ), Kiapu (Pistia stratiotes) dan Ketanan (Polygonum sp).
\end{abstract}

\section{Kata kunci : identifikasi tumbuhan air, danau Hanjalutung}

PENDAHULUAN

Danau Hanjaluntung terletak di Kelurahan Petuk Katimpun, Kecamatan Jekan Raya, Kota Palangka Raya Provinsi
Kalimantan Tengah. Danau Hanjalutung merupakan danau Oxbow yang terbentuk akibat aliran sungai yang terputus (sungai mati) dan sumber utama air Danau Hanjalutung adalah berasal dari sungai 
Rungan melalui satu inlet dari bagian utara (hulu) danau dan satu outlet dari bagian selatan (hilir). Luas Danau Hanjalutung sekitar 12 Ha (Tania, 2013).

Danau Hanjalutung merupakan danau atau sumber perairan yang dapat diberdayakan karena memiliki potensi penangkapan ikan yang cukup besar seperti konservasi, daerah penangkapan, dalam perikanan budidaya dan pariwisata (Nyata, 2012). Selain itu juga danau ini memiliki kelimpahan tumbuhan air yang beragam, baik mengapung dipermukaan atau yang berada dibawah permukaan seperti air seperti eceng gondok, kiambang, teratai, kangkung dan banyak tumbuhan air lainnya.

Tumbuhan air merupakan berbagai jenis tumbuhan air yang menempati suatu ekosistem perairan. Beberapa jenis tumbuhan air dianggap gulma atau tanaman pengganggu karena kecepatan pertumbuhannya yang tinggi dapat mempengaruhi ekosistem perairan. Danau Hanjalutung sebagian perairannya ditumbuhi dengan tumbuhan air. Keberadaan tumbuhan air yang hidup dengan baik akan meningkatkan produktifitas perairan, dan peranan tumbuhan air yang sangat penting adalah sebagai produsen primer, sebagai habitat biota seperti ikan, tempat perlindungan ikan, tempat menempel berbagai hewan dan tumbuhan atau alga. Selain itu tumbuhan air dapat berguna bagi biota pada perairan karena tumbuhan air dapat menjaga kualitas perairan (Kurniawan, 2012). Namun tidak semua tumbuhan air yang menguntungkan bagi perairan, ada sebagian tumbuhan air juga yang merugikan yaitu gulma air (Lauura, et all, 2017). Mengingat pentingnya peranan dari tumbuhan air tersebut, maka perlu dilalukan penelitian berupa inventarisasi dan identifikasi tumbuhan air di Danau Hanjalutung yang diharapkan dapat sebagai acuan untuk memberikan informasi tentang jenis-jenis tumbuhan air dan keberadaanya di Danau Hanjalutung.

\section{METODE PENELITIAN}

\section{Tempat dan Waktu Penelitian}

Penelitian dilaksanakan pada bulan Desember 2017 sampai Januari 2018 di Danau Hanjalutung Kelurahan Petuk Ketimpun, Kecamatan Jekan Raya, Kota Palangka Raya.
Alat dan Bahan
Peralatan dan bahan yang digunakan adalah perahu, tumbuhan air, GPS, ember, kamera, alat tulis, pisau, garis plastik, Transek $(2 \times 2 \mathrm{~m})$ dan buku identifikasi yaitu Aquatic Weeds of Southeast Asia 
dari Juan V. Pancho dan M. Soedani (1978).

\section{Penentuan Stasiun}

Stasiun pengamatan dilakukan dengan metode purposive sampling, yaitu teknik pengambilan sampel dengan maksud tertentu dimana lokasi pengambilan sampel tersebut mewakili perairan itu sehingga sampel yang diambil memiliki sifat yang sama (Nasoetion dan Barizi, 1998). Dan pengambilan sampel dilakukan di 3 (tiga) stasiun yaitu inlet (stasiun I) pada titik koordinat S $02^{\circ} 07^{\prime} 17.7^{\prime \prime}$ E $113^{\circ} 51$ ',52.2.”, bagian tengah (stasiun II) pada titik koordinat S 02 07'27.2” E 11351'49.9”, dan outlet (Stasiun III) pada titik koordinat S 02 07'28.28'E $113^{\circ} 52^{\prime} 12.5^{\prime \prime}$

\section{Pengambilan Sampel Tumbuhan Air}

Pengambilan sampel tumbuhan air di setiap stasiun penelitian terdapat 1 transek yang berukuran 2 × 2 meter yang dianggap dapat mewakili perairan danau Hanjalutung tersebut.

Tumbuhan diambil dari perairan secara perlahan-lahan agar bagian tanaman tidak mengalami kerusakan sehingga dapat diamati dengan jelas'

Jenis tumbuhan air yang telah diambil dan diamati kemudian di dokumentasi lalu dicocokan kembali dengan buku indentifikasi Aquatic Weeds of Southeast Asia (Juan V .Pancho \& Mohamad Soerjani, 1978).

\section{Analisis Data}

Data yang diperoleh dari hasil pengukuran di lapangan disajikan dalam bentuk tabulasi data kemudian dibahas dengan menggunakan literatur-literatur pendukung.

\section{HASIL DAN PEMBAHASAN}

Perairan Danau Hanjalutung pada dasarnya merupakan bagian dari perairan Sungai Rungan, dimana air yang surut atau pasang karena dipengaruhi oleh musim hujan. Sebagian kecil dari permukaan danau ditutupi berbagai jenis tumbuhan air seperti enceng gondok, kiambang, dan rumput para, tumput ekor kucing. Air danau berwarna kuning kehitaman hingga coklat kehitaman akibat kandungan humus tanah.

Tumbuhan air memiliki hubungan dan perannya yang relatif penting bagi komponen biotik lainnya di ekosistem perairan seperti ikan. Keberadaan tumbuhan air ini dari segi jenis maupun kelimpahannya dapat menjadi indikator kondisi lingkungan perairan tersebut (Astri Suryandari dkk, 2009). Tumbuhan air merupakan tumbuhan yang tinggal di sekitar air di dalam air yang berfungsi sebagai produsen penghasil energi pada 
suatu ekosistem (Odum dan Barrett, 2005 dalam Dian, 2013).

Secara umum, populasi tumbuhan air di Danau Hanjalutung pada waktu bulan Desember-Januari 2018 dapat dikatakan masih relatif rendah hal ini disebakan karena musim penghujan. Hal ini dapat mengakibatkan perubahan penyebaran komunitas tumbuhan air, hal ini seiring dengan Senny dkk (2008) bahwa perubahan tinggi muka air dapat mempengaruhi penyebaran populasi dan komunitas tumbuhan air di perairan.

Berdasarkan hasil penelitian yang dilaksanakan hanya ditemukan 7 (tujuh) jenis tumbuhan air. Dan berdasarkan hasil identifikasi buku Juan V. Pancho \& Mohamad Soerjani (1978) bahwa tumbuhan air di danau Hanjalutung termasuk kedalam tipe habitat tumbuhan air yang mengapung di perairan adalah kiambang (Salvinia molesta), eceng gondok (Eichhornia crassipes), kiapu (Pistia Stratiotes) dan tumbuhan air yang Tabel 1. Jenis Tumbuhan Air mencuat di atas perairan adalah gerigit (Leeersia hexandra), rumput ekor kucing (Utricularia aurea, ketanan (Polygonum.sp) dan rumput para (Cyperus platystylis). Hal ini seiring juga dengan Marson (2006) bahwa jenis tumbuhan air itu secara umum dikelompokkan menjadi 3 yaitu tumbuhan air mencuat, tenggelam dan mengapung. Disamping itu, tumbuhan air juga merupakan tempat hidup berbagai jenis periphyton dan serangga air yang merupakan sumber makanan bagi ikanikan yang hidup di perairan (Muhtarul, dkk. 2014). Odum dan Barrett (2005) menambahkan bahwa tanaman yang menyembul ini dapat membentuk rantai penting yang menghubungkan lingkungan darat dengan air dan memiliki distribusi hidup yang luas.

Hasil pengamatan berbagai jenis tumbuhan air dapat disajikan pada Tabel 1.

\begin{tabular}{|l|l|l|l|}
\hline No & Famili & Spesies & Nama Lokal \\
\hline 1 & Salviniaceae & Salvinia molesta & Kiambang \\
\hline 2 & Cyperaceae & Leeersia hexandra & Gerigit \\
\hline 3 & lentibulariaceae & Utricularia aurea & Rumput ekor kucing \\
\hline 4 & Cyperaceae & Cyperus platystylis & Rumput Para \\
\hline 5 & Pontederiaceae & Eichhornia crassipes & Eceng gondok \\
\hline
\end{tabular}




\begin{tabular}{|l|l|l|l|}
\hline 6 & Araceae & Pistia Stratiotes & Kiapu \\
\hline 7 & Polygonaceae & Polygonum.sp & Ketanan \\
\hline Jumlah Famili & 7 & \\
\hline Jumlah Spesies & 7 & \\
\hline
\end{tabular}

Berikut deskripsi dari jenis tumbuhan air Divisi : Pteridophyta yang terdapat di Danau Hanjalutung.

Kelas : Pteridopsida

\section{a. Kiambang (Salvinia molesta)}

Klasifikasi kiambang (Salvinia

Ordo : $\quad$ Salviniales

molesta) menurut buku identifikasi

Famili : Salviniaceae

Aquatic Weeds of Southeast Asia

Genus : Salvinia

(Soerjani dan Pancho, 1978).

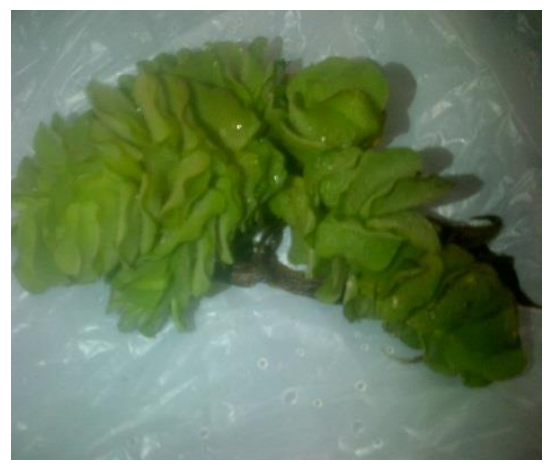

Gambar 1. Kiambang (Salvinia molesta)

\section{Deskripsi}

Kiambang (salvinia molesta) merupakan tumbuhan air yang mengapung bebas. Jumlah daun 12-20 helai pada cabang batang. Memiliki akar menggantung dan berbentuk serabut serta panjang akar $2 \mathrm{~cm}-7 \mathrm{~cm}$. memiliki rhizome atau rimpang berbatang tunggal, bercabang-cabang tidak beraturan dan beruas-ruas yang terletak di bawah permukaan air. Daun berwarna hijau muda dan pada bagian bawah daun dipenuhi bulu-bulu pendek berwarna coklat serta permukaan atas daun terdapat rambut halus untuk menjaga agar daun tidak basah (Soerjani dan Pancho, 1978).

b. Gerigit (Leersia hexandra)

Klasifikasi Gerigit (Leersia hexandra) menurut buku identifikasi 
Aquatic Weeds of Southeast Asia (Soerjani dan Pancho, 1978).

Divisi : Magnoliophyta

Kelas : Liliopsida

Ordo : Poales

Famili : Poaceae

Genus : Leersia

Spesies : Leersia hexandra

\section{Deskripsi}

Gerigit adalah tumbuhan air yang berakar di lumpur atau bertajuk di atas permukaan air, dengan ketinggian mencapai $0,5 \mathrm{~m}$, panjang daun $5-12 \mathrm{~cm}$ dan memiliki diameter batang 3,5-5 $\mathrm{mm}$. batang berbentuk rimpang, agak lunak, bagian pangkal biasanya menjalar dan memiliki akar. Bagian atas tumbuh tegak, berongga, licin atau agak berbulu pendek di bawah buku-buku. Helaian daun rata, agak kasar pada kedua sisi dan meruncing kearah ujung. Mempunyai rimpang yang merayap dalam tanah alat perkembangbiakan (Soerjani dan Pancho, 1978)

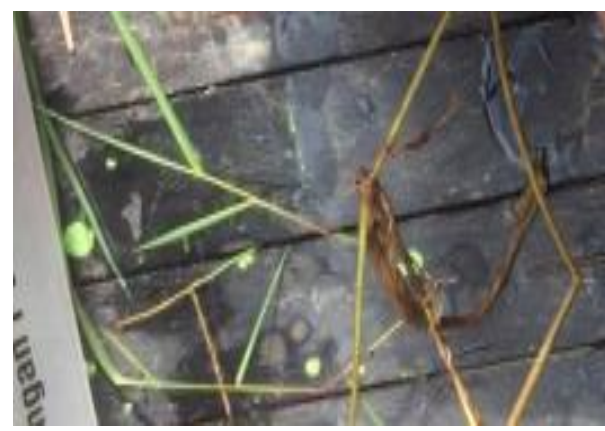

Gambar 2. Gerigit (Leersia hexandra)

\section{c. Rumput Ekor kucing (Utricularia} aurea)

Klasifikasi Rumput Ekor kucing

(Utricularia aurea) menurut buku identifikasi Aquatic Weeds of Southeast Asia (Soerjani dan Pancho, 1978).

Ordo : Lamiales

Famili : Lentibulariaceae

Genus : Utricularia

Spesies : $\quad$ Utricularia aurea

\section{Deskripsi}

Rumput ekor kucing (Utricularia aurea) adalah tanaman karnivora akuatik berukuran sedang sampai berukuran besar. Tumbuhan ini hidup dengan mengapung dan memiliki bunga berwarna kuning. Panjang setiap daun majemuk tumbuhan rumput ekor kucing bisa mencapai 1 meter. Tumbuhan ini dapat tumbuh di berbagai habitat. 


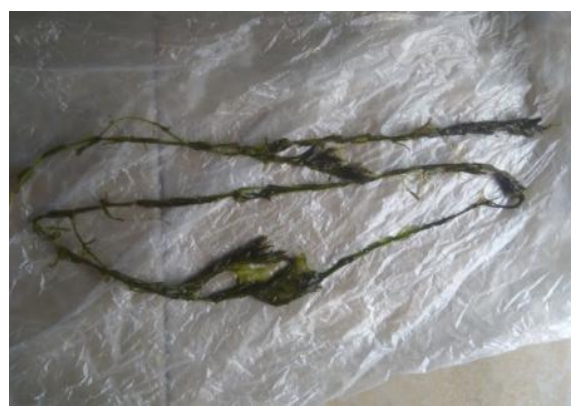

Gambar 3. Rumput Ekor kucing (Utricularia aurea)

\section{d. Rumput Para (Cyperus platystylis)}

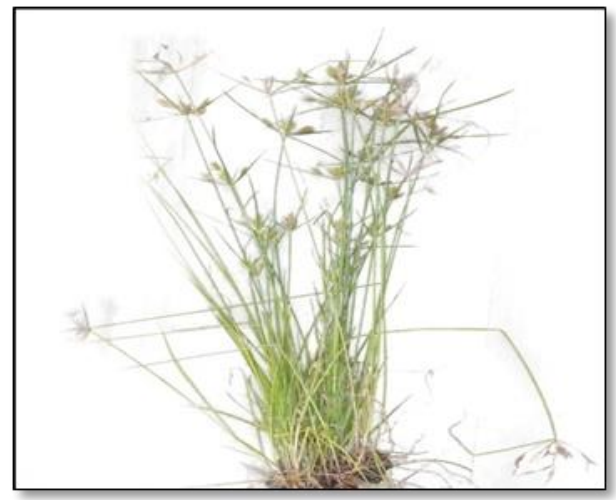

Gambar 4. Rumput Para (Cyperus platystylis)

Klasifikasi Rumput Para (Cyperus

platystylis) menurut buku identifikasi

Aquatic Weeds of Southeast Asia

(Soerjani dan Pancho, 1978).

Divisi : Magnoliophyta

Kelas : Liliopsida

Ordo : $\quad$ Cyperales

Famili : Cyperraceae

Genus : $\quad$ Cyperus

Spesies : $\quad$ Cyperus Platystylis

\section{Deskripsi}

Rumput para (Cyperus Platystylis) tumbuhan air yang memiliki akar tebal, batang kaku yang panjangnya sampai 1 meter, lunak pada bagian atas batang, tebal natang 3-8mm, daun hijau keabu-abuan, lebar daun 8-12 mm. Tumbuhan ini mudah patah, susunan bunga majemuk yang berbentuk seperti telur. Panjang tumbuhan air ini bisa mencapai $80 \mathrm{~cm}$. 


\section{e. Eceng Gondok (Eichhornia crassipes )}

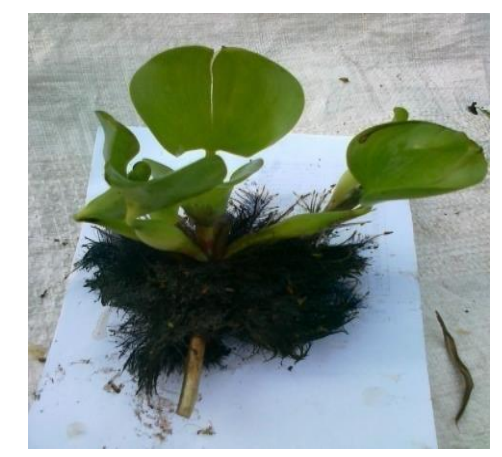

$\begin{array}{ll}\text { Kingdom } & : \text { Plantae } \\ \text { Division } & : \text { Magnoliophyta } \\ \text { Class } & : \text { Liliopsida } \\ \text { Order } & : \text { Liliales } \\ \text { Familiy } & : \text { Pontederiaceae } \\ \text { Genus } & : \text { Eichhornia } \\ \text { Species } & : \text { Eichhornia crassipes mart } \\ \text { Nama Latin } & : \text { Eichhornia crassipes mart } \\ \text { Nama Indonesia } & : \text { Eceng gondok }\end{array}$

Akar tanaman ini berambut dan menggantung pada pangkal batang, panjang akar $30 \mathrm{~cm}-60 \mathrm{~cm}$. Batang dan daunya penuh bilik udara yaitu rongga dinding penyekat selaput tipis berwarna putih. Selantar mudah terbentuk yang tumbuh dari ketiak daunya. Nantiny aselantar tersebut akan melepas diri dari tanaman induknya lalu menjadi tumbuhan baru yang berdiri sendiri. Helai daun bulat dan tangkai daun membengkak lunak seperti karet busa sehingga helai daun selalu mencul dipermukaan air. Bungan terdiri dari $4-6$ kuntum tiap tangkainya dengan warna ungu kebiruan, buah tidak pernah terbentuk. Karena keindahannya dengan warna bunga yang biru ungu, maka eceng gondok dimasukan oleh banyak negara sebagai tanaman hias. Dan menurut Chambers (1970) menyatakan bahwa $E$. crassipes merupakan jenis tumbuhan air yang memilki tingkat toleransi yang tinggi terhadap pencemaran. 


\section{f. Kiapu (Pistia stratiotes)}

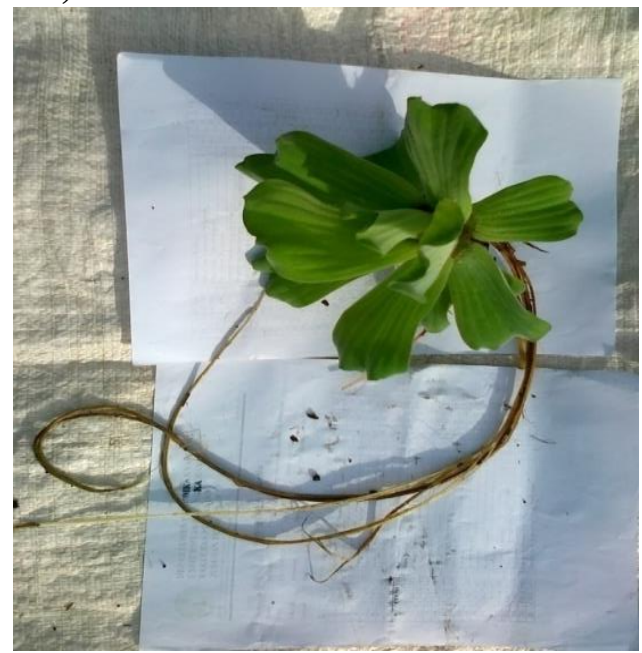

Kingdom : Plantae

Divisio : Magnoliophyta

Kelas : Liliopsida

Ordo : Arales

Familia : Araceae

Genus : Pistia

Spesies $\quad$ : Pistia Stratiotes L.

Nama latin $\quad$ : Pistia Stratiotes

Nama indonesia : Kiapu

Nama daerah : Apu-apu, Kol air

Susunan daunnya membentu roset

atau bertumpuk-tumpuk. Warnanya hijau

\section{g. Ketanan (Polygonum sp)}

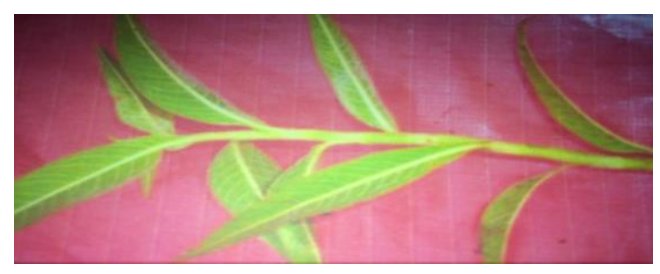

Gambar 7. Ketanan (Polygonum.sp)

Divisio : Spermatophyta

Klas : Angiospermae

Ordo : Polygonum linnaeus

Famili : Polygonaceae cerah dengan tekstur tebal berdaging serta berambut halus menyerupai bludru. Setiap roset daun tersebut dihubungkan oleh batang kecil menjalar pada stolon yang mudah dipotong. Ukuran rosetnya tidak terlalu besar, sekitar 10-15 cm. Akarnya yang menyerupai rambut tumbuh menggantung tepat dibawah roset daunnya. Dan tumbuhan air ini dapat bermanfaat sebagai bahan penyusun pakan alami pada ikan (Infa dkk, 2019).

Genus : Polygonum

Spesies : Polygonum barbatum

Nama lokal : Ketanan 
Ketanan (poliginum.sp) merupakan jenis tumbuhan berakar didasar dan bagian batang mencuat diatas permukaan air. Tumbuhan ini tumbuh tegak atau sedikit condong, dengann tinggi mencapai $30-60$ $\mathrm{cm}$, tumbuhan ini bercabang sedikit, bentuk daun mirip dengan anak tombak yaitu lonjong agak menyempit dan posisinya berselang - seling dengan induk tulang daun agak menonjol. Kuntum bungan mengelompok dalam tanda, bungan berwarna putih.

\section{KESIMPULAN}

Dari hasil penelitian yang dilakukan di perairan Danau Hanjalutung ditemukan 7 (tujuh) jenis tumbuhan air yaitu Kiambang (Salvinia molesta), gerigit (Leersia hexandra), Rumput Ekor Kucing (Utricularia aurea), Rumput Para (Cyperus platystylis), Eceng Gondok ( Eichhornia crassipes ), Kiapu (Pistia stratiotes) dan Ketanan (Polygonum sp).

Tumbuhan air tersebut ada yang mengapung di perairan adalah kiambang (Salvinia molesta) dan tumbuhan air yang mencuat di atas perairan adalah gerigit (Leeersia hexandra), rumput ekor kucing (Utricularia aurea) dan rumput para (Cyperus platystylis).

\section{DAFTAR PUSTAKA}

Astri Suryandari dan Yayuk Sugianti. 2009. Tumbuhan Air Di Danau Limboto, Gorontalo: Manfaat Dan Permasalahannya. Jurnal BAWAL: Vol.2 No.4-April 2009. Pusat Riset Perikanan.

Chambers, K. L. 1970. Biochemical coevolution. Twenty-ninth Biology Colloquium, Oregon state, University Press.Eugene.

Dian Ridwan Nurdiana. 2013. Inventarisasi tumbuhan air di Kebun Raya Cibodas. Depik, 2(1): 6-9 April 2013.

Infa Minggawati, Lukas, Youhandy, Yusanti Mantuh, Tania Serezova Augusta. 2019. Pemanfaatan Tumbuhan Apu-Apu (Pistia stratiotes) Untuk Menumbuhkan Maggot (Hermetia Illucens) Sebagai Pakan Ikan. Jurnal Ziraa'ah, Volume 44 Nomor 1, Pebruari 2019.

Kurniawan, Riky. 2012. Keragaman Jenis dan Penutupan Tumbuhan Air di Ekosistem Danau Tempe, Sulawesi Selatan. Pusat Penelitian Limnologi LIPI. Cibinong

Lauura Hermala Yunita, Efawani, Eddiwan. 2017. Identification of types and aquatic plantscoverage area in the Bandar Kayangan Lembah Sari Lake, Rumbai Pesisir Sub-Regency, Pekanbaru, Riau Province. Jurnal JOM, volume 3 .

Marson. 2006. Jenis Dan Peranan Tumbuhan Air Bagi Perikanan Di Perairan Lebak Lebung. .Jurnal 
BAWAL: Vol.1 No.2-Agustus 2006.

Muhtarul Abidin dan Mirna Dwirastina. 2014. Pengamatan Beberapa Jenis Vegetasi Tumbuhan Pada Perairan Rawaasam, Di Propinsi Bangka Belitung. BTL (Buletin Teknik Litkayasa). Vol.12 No. 2 Desember 2014

Nasoetion A. H. dan Bariz. 1998. Metode Statistika untuk Penarikan Kesimpulan. Sastra Budaya. Bogor.

Nyata Susila. 2012. Analisis Sosial Ekonomi masyarakat Kelurahan Petuk Ketimpun Dalam Mendukung Pemanfaatan Danau Hanjalutung Sebagai Kawasan Alternatif Pengembangan Usaha Perikanan di Kota Palangka Raya. Jurnal Ilmu Hewani Tropika Vol 1. No. 2. Desember 2012.

Odum, E.P., G. W. Barrett., 2005. Fundamentals of ecology. $5^{\text {th }}$ Edition. Thomson Learning, United State. 598 p.

Pancho, Juan V., and Muhammad S., 1978. Aquatic Weeds of Southeast Asia. Tropical Pest Biology. Program Biotrop, Seameo. Regional Center for Biology. Bogor.

Senny Sunanisari, Arianto Budi Santoso, Endang Mulyana, Sulung Nomosatryo dan Yayah Mardiyati. 2008. Penyebaran Populasi Tumbuhan Air Di Danau Singkarak. LIMNOTEK, 2008, Vol. XV, No. 2.

Soerjani, M dan Pancho, J.V. 1978. Aquatic Weeds of Southeast Asia. A System Account of Common Southeast Asian Aquatic Weeds. Nasional Pblishing Company. Quenzon city. Philipines.
Tania Serezova Augusta. 2013. Struktur Komunitas Zooplankton di Danau Hanjalutung Berdasarkan Jenis Tutupan Vegetasi. Jurnal Ilmu Hewani Tropika Vol 2. No. 2. Desember 2013. 